\title{
APPLIANCES
}

\section{NEW INSTRUMENTS FOR USE IN CATARACT EXTRACTION*}

\author{
BY \\ FERNANDO SILVÁN \\ Pamplona, Spain

\section{SuCtion Apparatus}

IN the adult, the suction extraction of cataracts, whether intumescent or not, is a valuable method, and I find it more satisfactory than the use of forceps, for which the indications are more limited. Many types of erisophake have been described, the majority having similar end-pieces but exerting suction by different methods: a simple rubber bulb (Pérez Llorca, 1947; Bell, 1948; Harrington, 1951; Esposito, 1953; McCoy, 1953; Silván, 1953, 1956; Moreno, 1954), an electrically powered suction pump (Barraquer, 1917), or accurately-fitted syringes with valves operated by hand or by a spring (Rochon-Duvigneaud and Noguès 1934; Lijó Pavía, 1936; Dimitry, 1941; Arruga, 1952). All these instruments function satisfactorily, and are used by various ophthalmologists according to their personal performance.

Although these instruments have their positive advantages they are not without their drawbacks. For example, the rubber bulb has to be pressed and released while the suction cup is being applied and this reduces the delicacy with which the cup can be applied to the lens. Mechanical suction seems to involve a disproportionate application of energy-a suction of several litres per minute being used for the removal of the lens weighing only about 25 centigrams - it is as if one were to call the fire brigade to put out a match (though this is not said with the object of detracting from the valuable work of the originators of this type of instrument). Finally, the syringe type of instrument requires awkward movements of the piston or valve to be made just as the surgeon's full attention should be given to the task of applying the cup to the lens.

To overcome these difficulties, I have devised a succession of different instruments, substituting a foot-control which leaves the hands free. Instruments have been similarly adapted for the diathermy treatment of retinal detachment, and for dacryocystorhinostomy. My earlier instruments have been modified according to the experience gained in their practical use, and the usefulness of the one described below has been proved in practice. Its principal features are perhaps more readily appreciated from the illustrations.

* Received for publication August 24, 1959. 
e $f$

d

b

a

e f

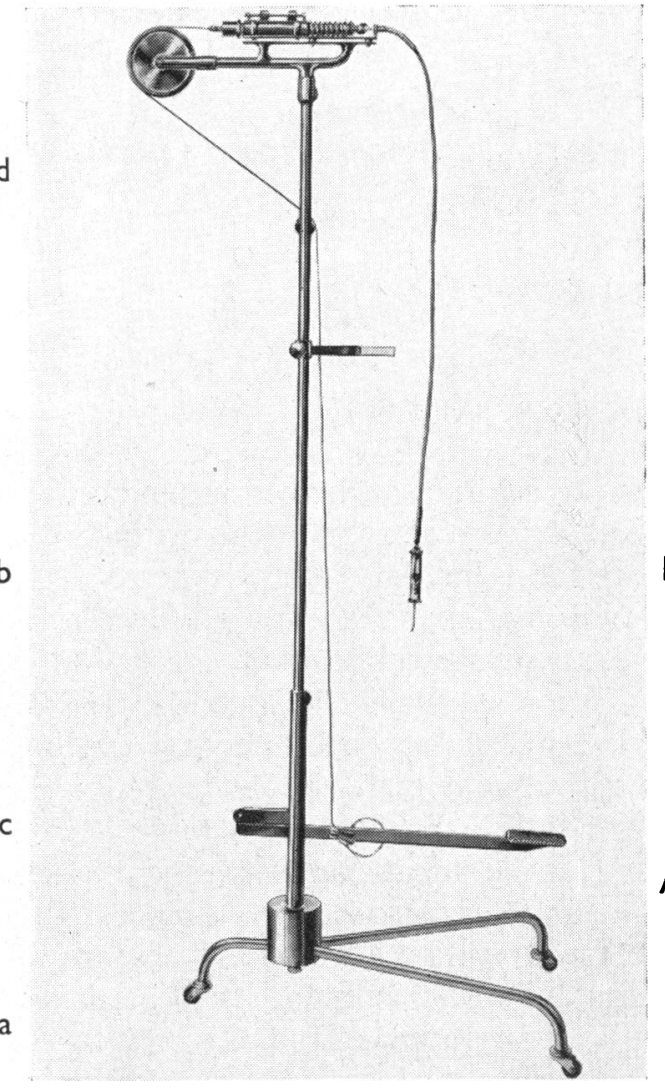

FIG. 1.-Pedal mechanism for cataract extraction

The instrument (Fig. 1) consists of two parts: a fixed support (A) and a detachable working mechanism (B). The support comprises a base (a) on which is mounted a vertical column (b). A pedal (c) working on the principle of a secondclass lever operates, by means of a cord (d), a movable cylinder (e) which slides like a piston in a fixed and shorter cylinder (f).

This piston mechanism is shown in detail in Fig 2. Press-

$B$ ure on the pedal pulls the cord (d), which withdraws the movable cylinder (e), and when the pressure is released a spring ( $g$ ) returns the cylinder to its original position. Adjustable stops $(h, h)$ regulate the excursion of $A$ the cylinder. The movable cylinder has two brackets $(i, j)$ for the attachment of the cable and its covering sheath (see Fig. 3). The cylinder (f) is fixed to the base-plate $(\mathrm{k})$. by suction.

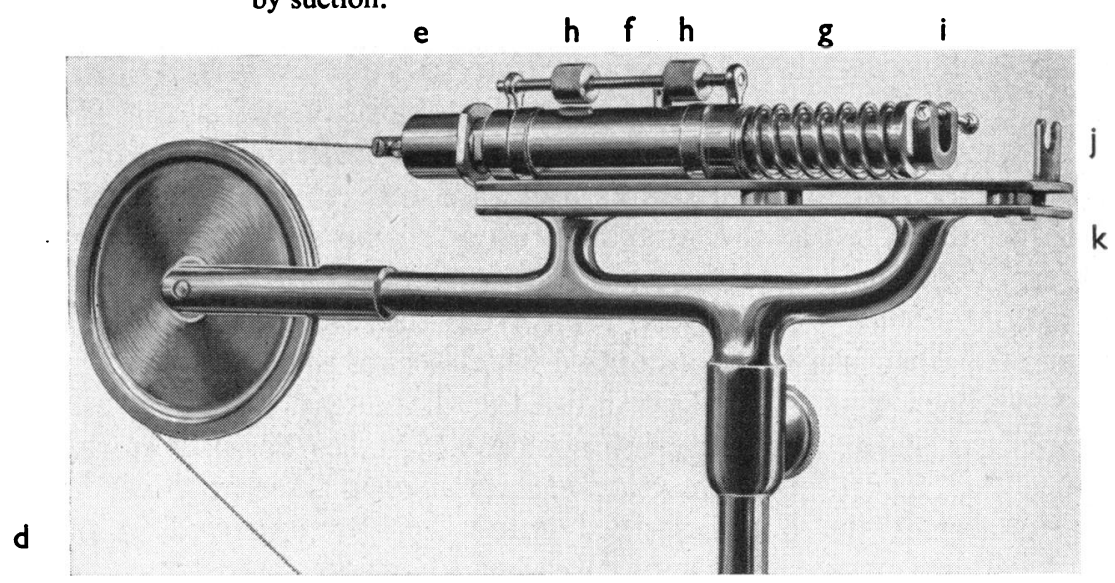

FIG. 2.-Fixed stand (A), showing cord (d), piston (e), cylinder (f), spring (g), and stops to regulate piston mechanism $(h, h)$. Brackets for the attachment of the cable and its sheath are shown at (i) and $(j)$. The whole cylinder is mounted on the base-plate (k). 
The movable part of the instrument (Fig. 3) consists of the suction cup (1), the syringe (m), a cable of stainless steel (n) running inside a metal sheath (o), and the attachments $\left(i_{2}, j_{2}\right)$, which connect the cable and its sheath to the stand.

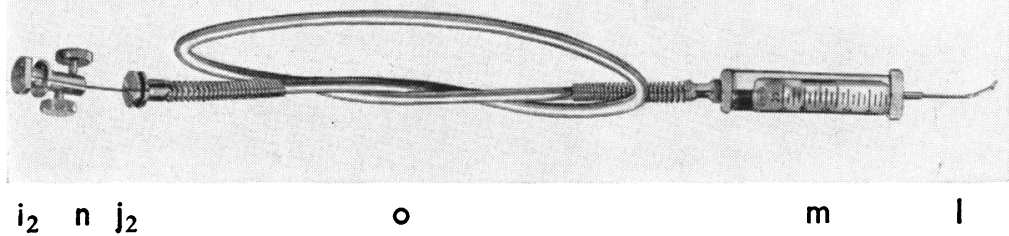

FIG. 3.-Suction cup (l) with syringe $(m)$ and the cable $(n)$ and its metallic sheath (o) with attachments $\left(i_{2}\right)$ and $\left(j_{2}\right)$ which are to be fitted into the brackets at (i) and (j) respectively. In this way the cable is joined to the movable piston (e) and the cable sheath to the fixed stand.

The movable part of the instrument, that is the syringe and cup together with the cable and its covering, can be sterilized either by formalin vapour or by prolonged immersion in alcohol. In the latter case the syringe should be cleaned by the aspiration of sterile water so that the last trace of alcohol is removed before the instrument is used.

The excursion of the piston is adjusted before use by setting the stops (h) and the instrument is ready for use. With very little pressure on the footpedal, the lens is picked up by the suction cup and may then be extracted without difficulty.

The ease with which the syringe, tube, and suction cup can be changed enables a series of cataract operations to be done one after the other with a fresh suction cup for each patient.

\section{CATARAct KNife}

Another instrument designed for cataract surgery is the "Inverted Knife" * (cuchillete inverso). This enables the corneal incision for the left eye to be performed using the right hand but with the surgeon in his usual position behind the head of the patient. Its use overcomes the difficulty that the surgeon has either to use the knife with his left or unskilled hand or to change his usual position. Figs 4 and 5 show the detachable blade intro-

Fig. 4.-Inverted knife.

* Made by Grieshaben, Schaffhausen, Switzerland. 


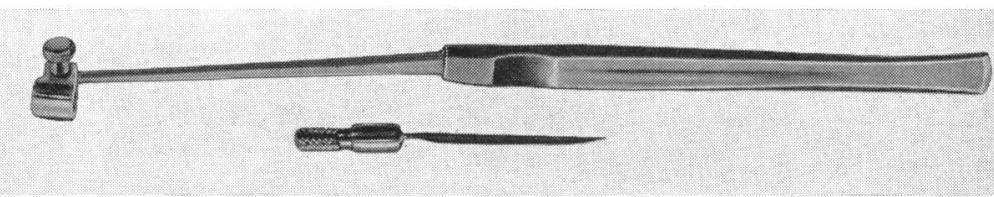

FIG. 5.--Inverted knife with blade dismounted.

duced into a clamp at the end of the knife handle. The handle is so shaped that the blade can be guided by the right hand, and the handle itself is angled so that it passes comfortably over the bridge of the nose.

\section{REFERENCES}

Arruga, H. (1952). “Ocular Surgery”, trans. from 3rd Spanish ed. by M. J. Hogan and L. E. Chaparro. Salvat, Barcelona; McGraw-Hill, New York.

BARRAQUER, I. (1917). Siglo méd., 64, 266, 740, 768.

Bell, A. E. (1948). Amer. J. Ophthal., 31, 610.

Dimitry, J. (1941). Cited by Arruga (1952), p. 560.

EsPosito, A. C. (1953) Brit. J. Ophthal., 37, 61.

HaRRINGTON, D. O. (1951). Amer. J. Ophthal., 34, 435, 1395.

Lijó Pavía, J. (1936). Rev. oto-neuro-oftal. (B. Aires), 11, 310.

McCoy, C. A. (1953). A.M.A. Arch. Ophthal., 50, 356.

MoReno, J. (1954). Arch. Soc. oftal. hisp.-amer., 14, 803.

Pérez LlorCA, J. (1947). Ibid. 7, 384.

Rochon-Duvigneaud, A., and Noquès, P. (1934). Bull. Soc. Ophtal. Paris, p. 643.

Santalices MuñIz, F. (1953). Arch. Soc. oftal. hisp-amer., 13, 570.

SilvÁN, F. (1953). Ibid., 13, 672

(1956). Ibid., 16, 795. 